\title{
Ozone comparison between Pandora \#34, Dobson \#061, OMI, and OMPS in Boulder, Colorado, for the period December 2013-December 2016
}

\author{
Jay Herman $^{1}$, Robert Evans ${ }^{2, *}$, Alexander Cede ${ }^{3}$, Nader Abuhassan ${ }^{1}$, Irina Petropavlovskikh ${ }^{4,5}$, Glenn McConville ${ }^{4,5}$, \\ Koji Miyagawa $^{\mathrm{a}}$, and Brandon Noirot ${ }^{4,5}$ \\ ${ }^{1}$ University of Maryland Baltimore County (JCET) at Goddard Space Flight Center, Greenbelt, MD, USA \\ ${ }^{2} \mathrm{NOAA} / \mathrm{ESRL} / \mathrm{GMD}$, Boulder, CO, USA \\ ${ }^{3}$ LuftBlick, Austria and Goddard Space Flight Center, Greenbelt, MD, USA \\ ${ }^{4}$ NOAA Earth System Research Laboratory, Boulder, CO, USA \\ ${ }^{5}$ Cooperative Institute for Research in Environmental Sciences (CIRES), University of Colorado, Boulder, CO, USA \\ ${ }^{a}$ visiting scientist at: at NOAA/ESRL/GMD, Boulder, CO, USA \\ * retired
}

Correspondence to: Jay Herman (jay.r.herman@ @asa.gov)

Received: 17 May 2017 - Discussion started: 23 May 2017

Revised: 28 August 2017 - Accepted: 29 August 2017 - Published: 27 September 2017

\begin{abstract}
A one-time-calibrated (in December 2013) Pandora spectrometer instrument (Pan \#034) has been compared to a periodically calibrated Dobson spectroradiometer (Dobson \#061) co-located in Boulder, Colorado, and compared with two satellite instruments over a 3-year period (December 2013-December 2016). The results show good agreement between Pan \#034 and Dobson \#061 within their statistical uncertainties. Both records are corrected for ozone retrieval sensitivity to stratospheric temperature variability obtained from the Global Modeling Initiative (GMI) and Modern-Era Retrospective analysis for Research and Applications (MERRA-2) model calculations. Pandora \#034 and Dobson \#061 differ by an average of $2.1 \pm 3.2 \%$ when both instruments use their standard ozone absorption cross sections in the retrieval algorithms. The results show a relative drift $\left(0.2 \pm 0.08 \% \mathrm{yr}^{-1}\right)$ between Pandora observations against NOAA Dobson in Boulder, CO, over a 3-year period of continuous operation. Pandora drifts relative to the satellite Ozone Monitoring Instrument (OMI) and the Ozone Mapping Profiler Suite (OMPS) are $+0.18 \pm 0.2 \% \mathrm{yr}^{-1}$ and $-0.18 \pm 0.2 \% \mathrm{yr}^{-1}$, respectively, where the uncertainties are 2 standard deviations. The drift between Dobson \#061 and OMPS for a 5.5-year period (January 2012-June 2017) is $-0.07 \pm 0.06 \% \mathrm{yr}^{-1}$.
\end{abstract}

\section{Introduction}

A Pandora spectrometer instrument \#034 (PSI, Pan \#034) located on top of the NOAA building in Boulder, Colorado, has been operating since December 2013 with little maintenance and using the original calibration. The purpose of this paper is to present a comparison between two co-located ozone measuring instruments, Pandora \#034 and Dobson \#061, for the period December 2013 to December 2016. Additional comparisons are made with satellite overpass data from OMI (Ozone Monitoring Instrument on board the Aura spacecraft) and OMPS (Ozone Mapping Profiler Suite on board the Suomi NPOESS satellite). This paper is an extension of a previously published paper (Herman et al., 2015) that presented just 1 year of data. The results demonstrate the accuracy and stability of both the Dobson and PSI for retrieval of total column ozone (TCO) and serve as a validation demonstration at one location for both the fairly new PSI and for satellite ozone data from OMI and OMPS. Part of the experiment comparing Pandora \#034 to Dobson \#061 was to see if Pandora \#034 would perform well over a long period without additional calibration or adjustments. The only change made during the period 2014 to the present (August 2017) was to replace a broken motor on the sun tracker that caused a data gap in early 2016. 


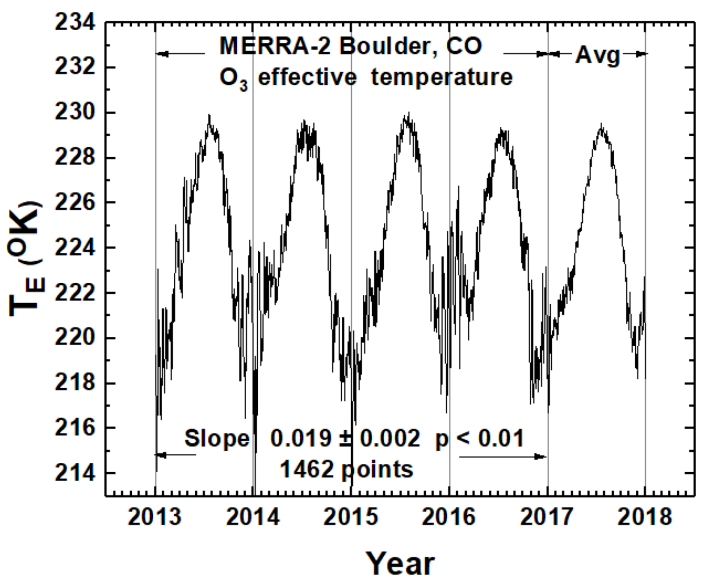

Figure 1. Calculated $T_{\mathrm{E}}$ using model estimates of $\mathrm{O}_{3}$ and temperature profiles. The trend is calculated from the difference of $T_{\mathrm{E}}$ from its 4-year daily mean, which is also used for year 2017, labelled Avg.

The characteristics of both the PSI and the Dobson spectroradiometer are described in Herman et al. (2015). Briefly, the PSI consists of a small Avantes low stray-light spectrometer $(280-525 \mathrm{~nm}$ with $0.6 \mathrm{~nm}$ spectral resolution with 5 times oversampling) connected to an optical head by a $400 \mu$ core diameter single-strand fiber optic cable. The spectrometer is temperature-stabilized at $20^{\circ} \mathrm{C}$ inside of a weatherresistant container. The optical head consists of a collimator and lens giving rise to a $2.5^{\circ}$ FOV (field-of-view) FWHM (full width at half maximum) with light passing through two filter wheels containing diffusers, an open hole, a UV340 filter (which blocks visible light), neutral density filters, and an opaque position (dark current measurement). The optical head is connected to a small sun tracker capable of accurately following the sun's center using a small computerdata logger contained in a weatherproof box along with the spectrometer. Pandora \#034 is capable of obtaining $\mathrm{NO}_{2}$ and TCO amounts sequentially over a period of $80 \mathrm{~s}$. The integration time in bright sun is about $4 \mathrm{~ms}$, which is repeated and averaged for $30 \mathrm{~s}$ to obtain a very high signal-to-noise ratio and an ozone precision of less than $1 \mathrm{DU}$, or $0.2 \%$ $\left(1 \mathrm{DU}=2.69 \times 10^{16}\right.$ molecules $\left.\mathrm{cm}^{-2}\right)$.

The Dobson record in Boulder started in 1966 based on an improved design from the instrument first deployed in the 1920s (Dobson, 1931). The Dobson instrument uses a differential absorption method to derive total column ozone from direct-sun measurements using two UV wavelength pairs in the 300-340 $\mathrm{nm}$ range (see Herman et al., 2015). The extensive Dobson network uses the Bass-Paur (BP) ozone absorption cross sections (Bass and Paur, 1985) for operational data processing (Komhyr et al., 1993).

All NOAA Dobson instruments are periodically calibrated against WMO world standard Dobson \#083, which in turn uses Langley method calibrations at the Mauna Loa Observa-

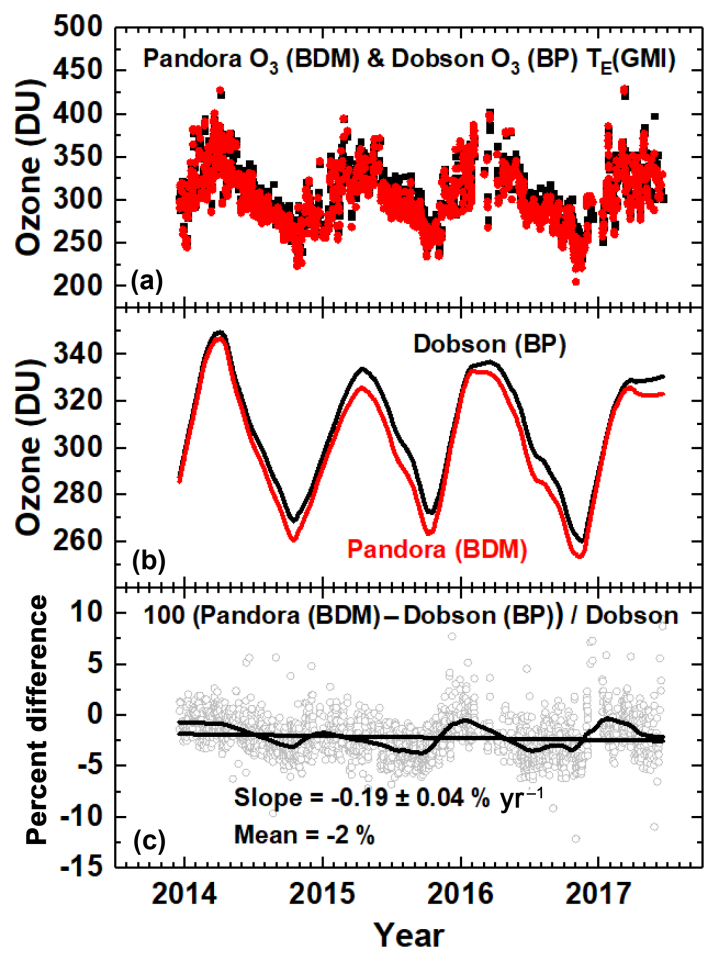

Figure 2. (a) shows the retrieved ozone time series (December 2013-June 2017) for Pandora (red) and Dobson (black). (b) shows a Lowess $(0.1)$ fit to the each time series. (c) shows the percent difference, a linear least-squares fit, and a Lowess (0.1) fit showing seasonal residuals.

tory station (Komhyr et al., 1989). Standard lamps are used to check Dobson spectral registration stability. Recently, in July 2017, intermediate calibrations from Dobson \#083 were applied to the Dobson \#061 ozone data record that improved its comparison with satellite data (the calibration updates were processed by one of the co-authors, Koji Miyagawa).

The main sources of noise in the PSI measurement comes from the presence of clouds or haze in the FOV, which increases the exposure time needed to fill the CCD wells to $80 \%$ and reduces the number of measurements in $30 \mathrm{~s}$. For this comparison study, data were selected for scenes under clear-sky conditions as determined from the Dobson A-D pair direct-sun data record.

Accuracy in the PSI spectral fitting retrieval is obtained using careful measurements of the spectrometer's slit function, wavelength calibration, and knowledge of the solar spectrum at the top of the atmosphere. The current operational PSI ozone retrieval algorithm used in this study is based on extraterrestrial solar flux from a combination of the Kurucz spectrum (wavelength resolution $\lambda / \Delta \lambda=500000$ ) radiometrically normalized to the lower-resolution shuttle ATLAS-3 SUSIM spectrum (Van Hoosier, 1996; Bernhard et al., 2004, 2005), Brion-Daumont-Malicet (BDM) ozone cross sections (Brion et al., 1993, 1998; Malicet et al. 1995), 

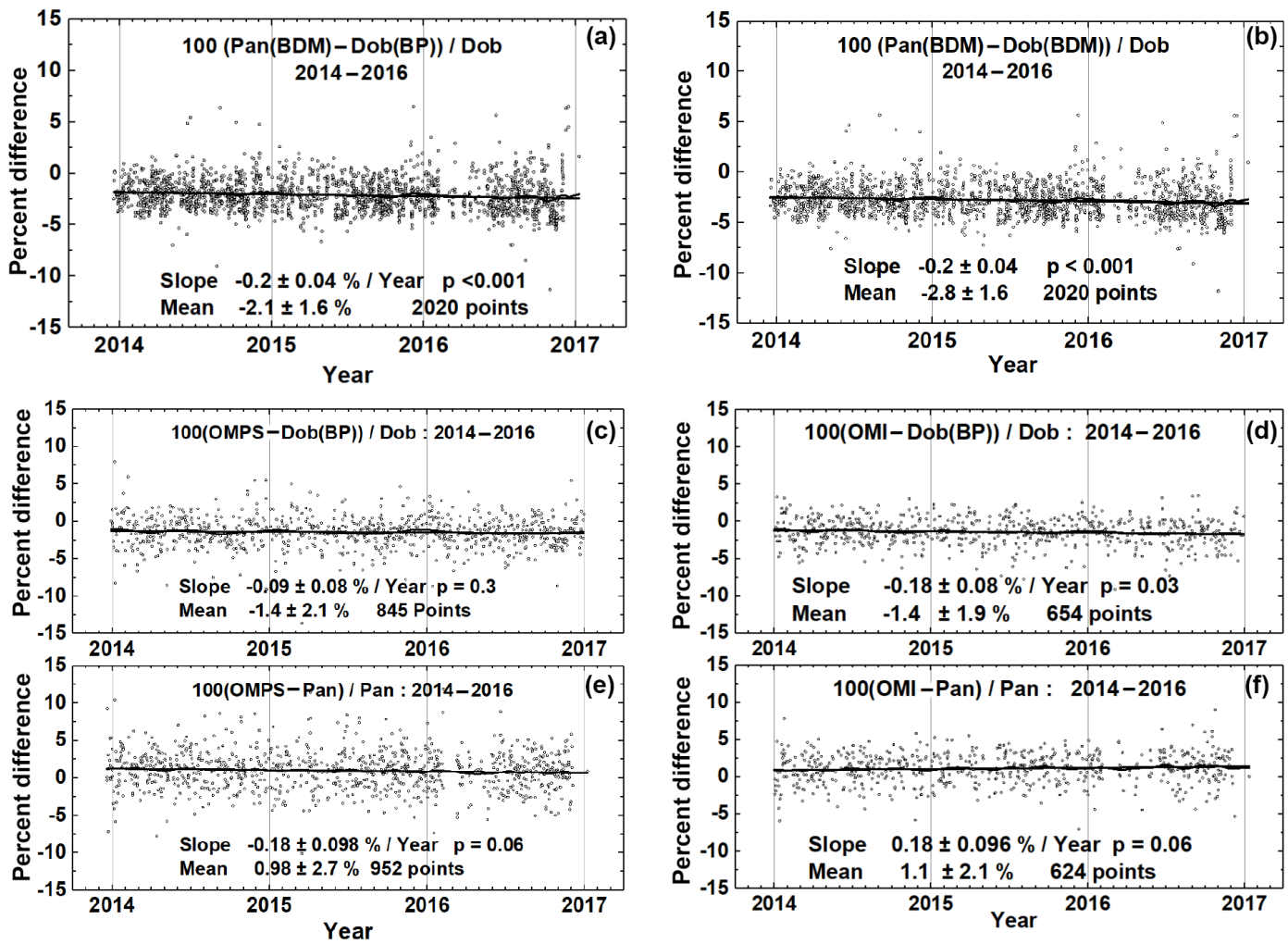

Figure 3. Comparisons of Pandora (BDM) with Dobson (BP and BDM) retrieved ozone for Boulder, Colorado, in percent differences of retrieved ozone and comparisons with OMI and OMPS. Slope is the value of the linear least-squares fit, $\pm N$ is $1 \mathrm{SD}$, and $p$ is the probability ( 0 to 1 ) that the slope is statistically different from 0 relative to $p=0.05$. The solid lines are a Lowess $(0.1)$ fit and a linear least-squares fit.

corrections for stray light, and an effective ozone-weighted temperature.

The Dobson data used in this study contain the individual measurements (more than one per day between 09:00 and 15:00 local time (LT) with almost all of the data between 10:00 and 14:00 LT) for clear-sky direct-sun observations using the quartz plate and A-D wavelength pairs for ozone retrieval (Dobson label ADDSGQP). These were made available by one of the co-authors (I. Petropavlovskikh, private communication, 2017 "Data availability" section). The NOAA Dobson total ozone data are typically archived at WOUDC (World Ozone and Ultraviolet Radiation Data Centre) or NDACC (Network for the Detection of Atmospheric Composition Change) with one representative ozone value per day.

\section{Temperature sensitivity}

The PSI ozone retrieval algorithm is more sensitive to the effective ozone-weighted average temperature than is the four-wavelength Dobson retrieval (Redondas et al., 2014). Neglecting the temperature sensitivity creates a seasonal difference between the two instruments. To correct for this, we use an effective ozone temperature $T_{\mathrm{E}}$ based on daily ozone-profile-weighted altitude temperature averages (Redondas et al., 2014). The temperature and ozone profile data were obtained from the GMI (Global Modeling Initiative) model calculation for 2012 to 2016 (https: //gmi.gsfc.nasa.gov/merra2hindcast/). The GMI model provides atmospheric composition hindcasts using MERRA-2 (Modern-Era Retrospective analysis for Research and Applications, Version 2, meteorology (Strahan et al., 2013; Wargan and Coy, 2016); https://gmao.gsfc.nasa.gov/reanalysis/ MERRA-2/). The simulation with $2 \times 2.5^{\circ}$ resolution uses the CCMI (Chemistry-Climate Modelling Initiative; Morgenstern et al., 2017) emissions and boundary conditions. MERRA-2 uses assimilation schemes based on hyperspectral radiation, microwave observations, and ozone satellite measurements. The resulting seasonal cycle for $T_{\mathrm{E}}$ shows variations over the 4-year period, while day-to-day variability is enhanced during winter and spring seasons (Fig. 1). An estimated fifth year (2017) has been added (Fig. 1) by forming the average of the daily temperatures from the 2013-2016 period.

The $T_{\mathrm{E}}$ time series data are used for an ozone retrieval temperature correction $\left(\mathrm{TCO}_{\text {corr }}\right.$ coefficient) given in the form $\mathrm{TCO}_{\text {corr }}=\mathrm{TCO}(1+\mathrm{C}(T))$ and $\mathrm{O}_{3}$ (corr) $=\mathrm{O}_{3} \mathrm{TCO}_{\text {corr }}$ (Herman et al., 2015), where $\mathrm{C}\left(T_{\mathrm{E}}\right)$ is given by Eqs. (1) and 


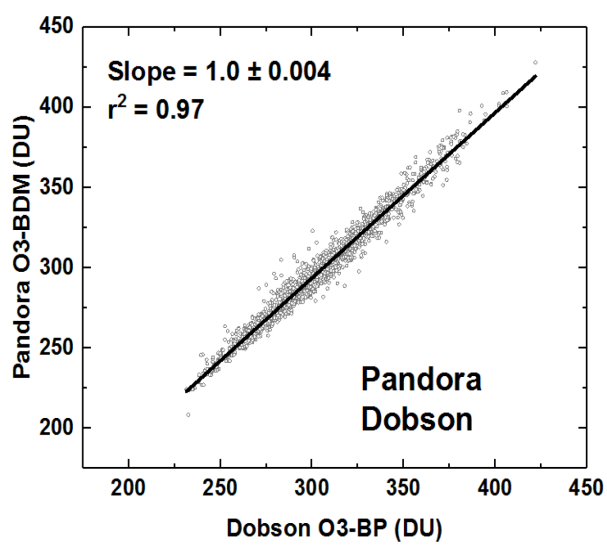

Figure 4. Correlation between Pandora \#034 and Dobson \#061 for 2014-2016.

(2).

$\mathrm{C}_{\text {Pandora-BDM }}\left(T_{\mathrm{E}}\right)=0.00333\left(T_{\mathrm{E}}-225\right)$

(Herman et al., 2015),

$\mathrm{C}_{\text {Dobson-BP }}\left(T_{\mathrm{E}}\right)=-0.0013\left(T_{\mathrm{E}}-226.7\right)$

(Redondas et al., 2014),

$\mathrm{C}_{\text {Dobson-BDM }}\left(T_{\mathrm{E}}\right)=0.00042\left(T_{\mathrm{E}}-226.7\right)$

(Redondas et al., 2014).

As mentioned earlier, the Dobson TCO retrieval normally uses the Bass and Paur (BP) ozone absorption coefficients, while Pandora uses the BDM coefficients. A change in $T_{\mathrm{E}}$ of $+1^{\circ}$ leads to TCO changes for the Pandora (BDM), Dobson (BP), and Dobson (BDM) instruments of $+0.33,-0.13$, and $0.042 \%$, respectively. For a nominal TCO value of $325 \mathrm{DU}$, the change would be +1.1 and $-0.4 \mathrm{DU}$, a net relative change of $1.5 \mathrm{DU}$ for a $1^{\circ} \mathrm{K}$ change between Pandora (BDM) and Dobson (BP).

While BDM cross sections are not currently recommended for use in standard Dobson processing, their use yields slightly different values of TCO and a smaller sensitivity to temperature. The basic Dobson algorithm, based on pairs of wavelengths, is intrinsically less sensitive to $T_{\mathrm{E}}$ than Pandora's spectral fitting retrieval.

\section{TCO comparisons between Pandora, Dobson, OMI, and OMPS}

Comparing retrieved TCO from the PSI, Dobson, OMI, and OMPS instruments shows that there are small but significant differences between the PSI and Dobson instruments and between the ground-based instruments and satellite-derived values of TCO. The difference is calculated using 3-year estimates of secular change based on a linear least-squares fit to the percent differences (PDs) between the instruments. The cloud-free direct-sun A-D pair Dobson ozone data are se- lected for comparison with time-matched Pandora \#034 retrieved ozone data (Herman et al., 2015). The Pandora \#034 retrieved ozone (every $80 \mathrm{~s}$ ) are matched to the less frequent Dobson \#061 retrieval times that are obtained for midday solar zenith angles (SZAs) and averaged over \pm 8 min (Fig. 2a).

Each clear-sky PSI data point is an average of 2000 (early morning to evening SZAs) to 4000 (midday SZAs) measurements obtained during $30 \mathrm{~s}$. All data for this study were clear sky within the instrument's field of view based on the Dobson criteria for A-D-pair direct-sun clear sky. In addition, the PSI data are averaged over a period of \pm 8 min surrounding the Dobson time of measurement (two to three times per day). Since PSI measurements are obtained every $80 \mathrm{~s}$, there were an additional 10 PSI data points averaged together to compare to each Dobson, OMI, or OMPS measurement. The result is high signal-to-noise values for Pandora and high precision $(0.1 \%)$. The same procedure using cloud-screened PSI data was used for comparisons with OMI and OMPS, where they measure once or twice per day over Boulder, Colorado. Some of the variations in the day-to-day ozone values are driven by changes in the local weather over Boulder, Colorado (see Fig. 14 in Herman et al., 2015), with weekly averages having much smaller variation.

Figure $2 \mathrm{~b}$ shows a Lowess $(0.1)$ fits to the two time series in Fig. 2a that is approximately equivalent to a 3-month running average. The Lowess (f) procedure is based on local least-squares fitting using low-order polynomials applied to a specified fraction $f$ of the data (Cleveland, 1979) that reduces the effect of outlier points from the mean. The smooth curves show a small variable difference between the Dobson and Pandora time series. Figure $2 \mathrm{c}$ shows the PD between the time series in Fig. 2a and the residual seasonal variation in PD. Estimating the slope of the least-squares fit to the percent difference can be sensitive to the selection of the end points of the time series. This effect can be minimized by removing the seasonal time dependence (Fig. 2c) using a lowpass filter function with zero slope derived from the Lowess (0.1) fit. The result is shown in Fig. 3a.

Figure 3 shows the de-seasonalized PD (A, B) for six pairs between Pandora \#034, Dobson \#061, OMI, and OMPS for the 3-year period 2014-2016 (summarized in Table 1). The slightly curvy Lowess (0.1) lines about each linear fit show the residual seasonal cycles, which are too small to have an effect on slope determination. Error estimates (Fig. 3 and Table 1) for the linear least-squares slopes and averages are 1 standard deviation (SD). Some of the error estimates are large enough to make the statistical significance of the slopes marginal (see Fig. 3e OMPS vs. Pandora; $0.18 \pm 0.098$, $p=0.06$ ), while others are significant (see Fig. 3d OMI vs. Dobson: $-0.18 \pm 0.08, p=0.03$ ) at the 2 SD level. The significance probability parameter $p$ is given, where $p$ is the probability ( 0 to 1 ) that the slope is statistically different from 0 relative to $p=0.05$. Also shown are the numbers of data points in each time series. 

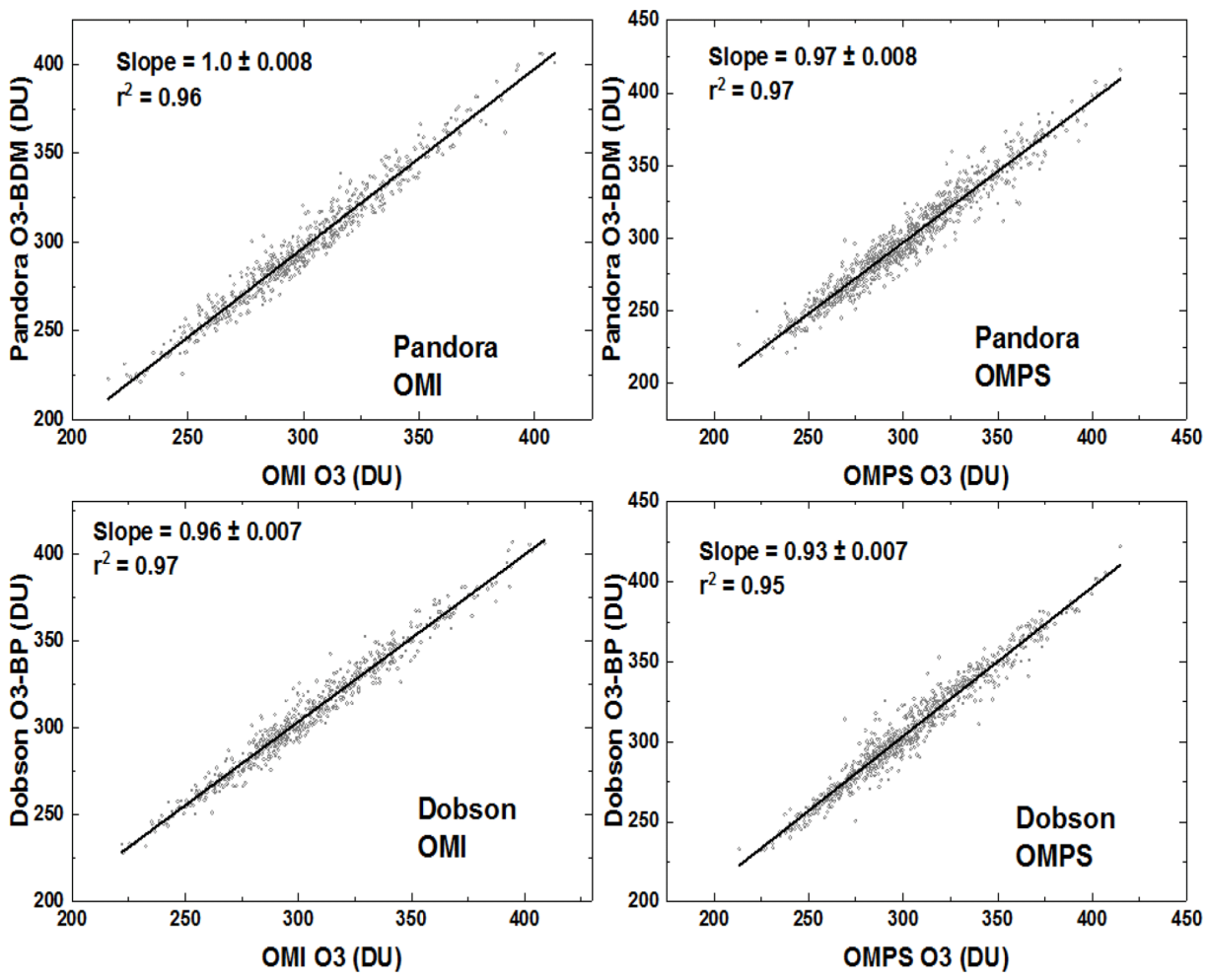

Figure 5. Correlation of Pandora \#034 and Dobson \#061 with OMI and OMPS for 2014-2016.

Table 1. Percent difference summary of linear fit slopes and mean differences in Fig. 3.

\begin{tabular}{lrrrrl}
\hline Percent diff (A, B) & Slope $\left(\% \mathrm{yr}^{-1}\right)$ & Probability & Mean $(\%)$ & Points & Panel \\
\hline Pan, Dob (BP) & $-0.2 \pm 0.04$ & $P<0.001$ & $-2.1 \pm 1.6$ & 2020 & A \\
Pan, Dob (BDM) & $-0.2 \pm 0.04$ & $P<0.001$ & $-2.8 \pm 1.6$ & 2020 & B \\
OMPS, Dob (BP) & $-0.09 \pm 0.08$ & $P=0.3$ & $-1.4 \pm 2.1$ & 854 & C \\
OMI, Dob (BP) & $-0.18 \pm 0.08$ & $P=0.03$ & $-1.4 \pm 1.9$ & 654 & D \\
OMPS, Pan & $-0.18 \pm 0.098$ & $P=0.06$ & $0.96 \pm 2.7$ & 952 & E \\
OMI, Pan & $+0.18 \pm 0.096$ & $P=0.06$ & $1.1 \pm 2.1$ & 624 & F \\
\hline
\end{tabular}

After removal of the residual seasonal variation in the calculated percent differences, there still is a statistically significant drift of $0.2 \% \mathrm{yr}^{-1}(p<0.001)$ between the Pandora \#034 and Dobson \#061 (Fig. 3a, b) using either BP or BDM ozone cross sections for Dobson \#061. The differences in the mean values $(-2.1$ and $-2.8 \%)$ are not significant at the 2 SD level.

The linear trend (Fig. 3c, $-0.09 \pm 0.08 \% \mathrm{yr}^{-1}, p=0.3$ ) between the Dobson and OMPS is not significantly different from zero, while the drift with OMI (Fig. 3d, $\left.-0.18 \pm 0.08 \% \mathrm{yr}^{-1}, p=0.03\right)$ is significant. This suggests that OMI ozone retrievals are drifting with respect to OMPS and the Dobson. Extending the period from 2012 to June 2017 gives a very small but significant trend, $-0.07 \pm 0.03 \% \mathrm{yr}^{-1}, p=0.047$, for PD (OMPS, Dobson).

Calculations for Pandora \#034 (Fig. 3e, f) show marginally significant $(p=0.06)$ trends for Pandora \#034 compared to
OMPS (Fig. 3e, $-0.18 \pm 0.098 \% \mathrm{yr}^{-1}$ ) and OMI (Fig. 3f, $+0.18 \pm 0.096 \% \mathrm{yr}^{-1}$ ). If the Pandora \#034 time series is extended into 2017 to minimize the effect of missing Pandora data in 2016, then the trends for Pandora compared to OMPS $\left(-0.2 \pm 0.08 \% \mathrm{yr}^{-1}, p=0.013\right)$ and OMI $(0.15 \pm 0.076$, $p=0.05)$ are significant, but not different from the shorter 2014-2016 period. The secular trends for the difference between Pandora \#034 and Dobson \#061 ( $-0.2 \%$ per year) are almost the same for both Dobson BP and BDM ozone absorption coefficients even though the temperature sensitivity using the Dobson BDM ozone absorption coefficients is small $\left(0.042 \%{ }^{\circ} \mathrm{C}^{-1}\right)$. This suggests that the stratospheric effective ozone temperature change is not a source for the small differences between Pandora \#034 and Dobson \#061.

Figure 4 shows that the TCO between Pandora \#034 and Dobson \#061 is highly correlated with 1:1 slope, and the correlation coefficient $r^{2}=0.97$ for the 3 -year period 2014 
to 2016. Similar correlation plots (Fig. 5) for Pandora \#034 and Dobson \#061 with OMI and OMPS also show very high correlations. The correlations in TCO are obtained after only temperature corrections to Pandora \#034 and Dobson \#061 using $T_{\mathrm{E}}$ (TCO pairs similar to Fig. 2a).

The Pandora, OMI, and OMPS data used in this study are from the overpass files located on the public websites ("Data availability" section).

\section{Summary}

Temperature-corrected Pandora \#034 and Dobson \#061 differ by an average of $2.1 \pm 3.2 \%$, with Pandora using its standard retrieval BDM ozone absorption cross sections and Dobson using the recommended BP ozone absorption cross sections. Pandora, as compared to Dobson, shows a small but significant drift $\left(-0.2 \pm 0.08 \% \mathrm{yr}^{-1}, p<0.001\right)$ for the 2014-2016 period. Comparisons of Pandora with OMI and OMPS are marginally significant drifts of $0.18 \pm 0.2$ and $-0.18 \pm 0.2(p=0.06)$ for 2014-2016, but they are significant $\left(0.15 \pm 0.15 \% \mathrm{yr}^{-1}, p=0.05\right.$, and $-0.2 \pm 0.16 \% \mathrm{yr}^{-1}$, $p=0.013$, respectively) if the period is extended to mid2017 to minimize the effect of missing Pandora data during 2016. The small Pandora and Dobson trends compared to OMPS suggest that both instruments are stable. The conclusion is that the periodically calibrated Dobson \#061 is able to detect smaller ozone trends than a Pandora instrument with no intermediate calibration during a 3-year period. The longer-term trend for Dobson compared to OMPS for a 5.5-year period (2012-June 2017) is $-0.07 \pm 0.06 \% \mathrm{yr}^{-1}$, $p=0.047$. All error estimates are $2 \mathrm{SD}$.

Data availability. The data used in this study are available from the following sources: $\mathrm{OMI} \mathrm{O}_{3}$ Overpass Data (GSFC OMI Project): https://avdc.gsfc.nasa.gov/index.php?site $=1593048672 \&$ id_ =_28/aura_omi_12ovp_omto3_v8.5_boulder.co_067.txt.

NPP $\mathrm{O}_{3}$ Overpass Data (GSFC NPP Project): ftp: //toms.gsfc.nasa.gov/pub/omps_tc/overpass/suomi_npp_omps_ 12ovp_nmto3_v02_boulder.co_067.txt. Pandora Data (Herman, 2017): https://avdc.gsfc.nasa.gov/pub/DSCOVR/Pandora/DATA/ Boulder/Pandora34/L3c/. Dobson Data (Petropavlovskikh, 2017): ftp://aftp.cmdl.noaa.gov/data/ozwv/Dobson/WinDobson/ Pandoracomparisons/Dobson61BoulderAd-dsgqp120213-032717_ w_Header.txt.

Competing interests. The authors declare that they have no conflict of interest.

Special issue statement. This article is part of the special issue "Quadrennial Ozone Symposium 2016 - Status and trends of atmospheric ozone (ACP/AMT inter-journal SI)". It is a result of the Quadrennial Ozone Symposium 2016, Edinburgh, United Kingdom, 4-9 Sep 2016.
Acknowledgements. The authors would like to thank Susan Strahan and the MERRA-2 team for supplying the atmospheric temperature data for Boulder, Colorado.

Edited by: Stefan Reis

Reviewed by: Robert Chatfield and two anonymous referees

\section{References}

Bass, A. M. and Paur, R. J.: The ultraviolet cross-sections of ozone, I, The measurements, in: Atmospheric Ozone, edited by: Zerefos, C. S., Ghazi, A., and Reidel, D., Norwell, Mass., 606-610, 1985.

Bernhard, G., Booth, C. R., and Ehramjian, J. C.: Version 2 data of the National Science Foundation's Ultraviolet Radiation Monitoring Network: South Pole, J. Geophys. Res., 109, D21207, https://doi.org/10.1029/2004JD004937, 2004.

Bernhard, G., Evans, R. D., Labow, G. J., and Oltmans, S. J.: Bias in Dobson total ozone measurements at high latitudes due to approximations in calculations of ozone absorption coefficients and air mass, J. Geophys. Res, 110, D10305, https://doi.org/10.1029/2004JD005559, 2005.

Brion, J., Chakir, A., Daumont, D., Malicet, J., and Parisse, C.: High-resolution laboratory absorption cross section of O3 Temperature effect, Chem. Phys. Lett., 213, 610-612, 1993.

Brion, J., Chakir, A., Charbonnier, J., Daumont, D., Parisse, C., and Malicet, J.: Absorption spectra measurements for the ozone molecule in the 350-830 nm region, J. Atmos. Chem., 30, 291299, 1998.

Cleveland, W. S.: Robust Locally Weighted Regression and Smoothing Scatterplots, J. Am. Stat. Assoc., 74, 829-836, 1979.

Dobson, G. M. B.: A photoelectric spectrophotometer for measuring the amount of atmospheric ozone, Proc. Phys. Soc., 43, 324339, 1931.

Herman, J. R., Evans, R. D., Cede, A., Abuhassan, N. K., Petropavlovskikh, I., and McConville, G.: Comparison of Ozone Retrievals from the Pandora Spectrometer System and Dobson Spectrophotometer in Boulder Colorado, Atmos. Meas. Tech., 8, 3407-3418, https://doi.org/10.5194/amt-8-3407-2015, 2015.

Komhyr, W. D., Grass, R. D., and Leonard, R. K.: Dobson spectrophotometer 83: A standard for total ozone measurements, 1962-1987, J. Geophys. Res., 94, 9847-9861, https://doi.org/10.1029/JD094iD07p09847, 1989.

Komhyr, W. D., Mateer, C. L., and Hudson R. D.: Effective BassPaur 1985 ozone absorption coefficients for use with Dobson ozone spectrophotometers, J. Geophys. Res., 98, 20451-20465, https://doi.org/10.1029/93JD00602, 1993.

Malicet, J., Daumont, D., Charbonnier, J., Parisse, C., Chakir, A., and Brion, J.: Ozone UV spectroscopy. II. Absorption cross sections and temperature dependence, J. Atmos. Chem., 21, 263273, 1995.

Morgenstern, O., Hegglin, M. I., Rozanov, E., O’Connor, F. M., Abraham, N. L., Akiyoshi, H., Archibald, A. T., Bekki, S., Butchart, N., Chipperfield, M. P., Deushi, M., Dhomse, S. S., Garcia, R. R., Hardiman, S. C., Horowitz, L. W., Jöckel, P., Josse, B., Kinnison, D., Lin, M., Mancini, E., Manyin, M. E., Marchand, M., Marécal, V., Michou, M., Oman, L. D., Pitari, G., Plummer, D. A., Revell, L. E., Saint-Martin, D., Schofield, R., Stenke, A., Stone, K., Sudo, K., Tanaka, T. Y., Tilmes, 
S., Yamashita, Y., Yoshida, K., and Zeng, G.: Review of the global models used within phase 1 of the Chemistry-Climate Model Initiative (CCMI), Geosci. Model Dev., 10, 639-671, https://doi.org/10.5194/gmd-10-639-2017, 2017.

Redondas, A., Evans, R., Stuebi, R., Köhler, U., and Weber, M.: Evaluation of the use of five laboratory-determined ozone absorption cross sections in Brewer and Dobson retrieval algorithms, Atmos. Chem. Phys., 14, 1635-1648, https://doi.org/10.5194/acp-14-1635-2014, 2014.

Strahan, S. E., Douglass, A. R., and Newman, P. A.: The contributions of chemistry and transport to low Arctic ozone in March 2011 derived from Aura MLS Observations, J. Geophys. Res., 118, 1563-1576, https://doi.org/10.1002/jgrd.50181, 2013.
Van Hoosier, M. E.: Solar ultraviolet spectral irradiance data with increased wavelength and irradiance accuracy, SPIE Proc., 2831, 57-64, 1996.

Wargan, K. and Coy, L.: Strengthening of the Tropopause Inversion Layer during the 2009 Sudden Stratospheric Warming: A MERRA-2 Study, J. Atmos. Sci., 73, 1871-1887, https://doi.org/10.1175/JAS-D-15-0333.1, 2016. 